Research Article

\title{
On Some Properties of Multiplicative Topological Indices in Silicon-Carbon
}

\author{
Abid Mahboob $\mathbb{D},{ }^{1}$ Sajid Mahboob, ${ }^{2}$ Mohammed M. M. Jaradat $\mathbb{D}^{\circ},{ }^{3}$ Nigait Nigar, ${ }^{2}$ \\ and Imran Siddique $\mathbb{1}^{4}$ \\ ${ }^{1}$ Department of Mathematics, Division of Science and Technology, University of Eduction, Lahore, Pakistan \\ ${ }^{2}$ Department of Mathematics, Minhaj University, Lahore, Pakistan \\ ${ }^{3}$ Mathematics Program, Departement of Mathematics, Statistics and Physics, College of Arts and Sciences, Doha 2713, Qatar \\ ${ }^{4}$ Department of Mathematics, University of Management and Technology, Lahore 54770, Pakistan
}

Correspondence should be addressed to Mohammed M. M. Jaradat; mmjst4@qu.edu.qa

Received 13 September 2021; Accepted 7 October 2021; Published 8 November 2021

Academic Editor: Ali Ahmad

Copyright ( $\odot 2021$ Abid Mahboob et al. This is an open access article distributed under the Creative Commons Attribution License, which permits unrestricted use, distribution, and reproduction in any medium, provided the original work is properly cited.

The use of graph theory can be visualized in nanochemistry, computer networks, Google maps, and molecular graph which are common areas to elaborate application of this subject. In nanochemistry, a numeric number (topological index) is used to estimate the biological, physical, and structural properties of chemical compounds that are associated with the chemical graph. In this paper, we compute the first and second multiplicative Zagreb indices $\left(M_{1}(G)\right.$ and $\left.\left(M_{1}(G)\right)\right)$, generalized multiplicative geometric arithmetic index $\left(\mathrm{GA}^{\alpha} \mathrm{II}(G)\right)$, and multiplicative sum connectivity and multiplicative product connectivity indices (SCII $(G)$ and $\operatorname{PCII}(G))$ of $\mathrm{SiC}_{4}-I[m, n]$ and $\mathrm{SiC}_{4}-\mathrm{II}[m, n]$.

\section{Introduction}

Chemical graph theory is the branch in which mathematical chemistry is concerned with nontrivial graphs and its applications in molecular issues. The major purpose of chemical graph theory is to employ algebraic invariants to reduce a molecule's topological structure to a single number which characterizes to the molecule's energy, orbitals, molecular branching, structural fragments, and electronic structures, among others. The topological index is a numerical value associated with chemical constitutions that suggest a link between chemical structures and a variety of physical qualities which measure chemical reactivity or biological activity. Topological indices are also called molecular descriptor. They are used to investigate certain physical features of a molecule by analyzing mathematical values. As a result, it is an effective way to eliminate costly and time-consuming laboratory trials. Molecular descriptors play an important role in mathematical chemistry, especially in quantitative structure relationships (QSAR) and quantitative structure activity relationship (QSAR) investigation.

There are some other valueable structure problems existing in real life which can be addressed by graphical representation such as optimal frequency assignments in Radio (see $[1,2])$. The topological indices are beneficial to justify the characteristics of chemical compounds such as melting, boiling, and flash points; other properties such as heat of formation, heat of vaporization, density, and pressure can also be estimated by these graph invariants. Due to great significance, it attracts the interest of many researchers. The first topological index was Wiener index given by Harnold Wiener in 1947 [2]. Some Zagreb indices are very close to the wiener index [3], Gutman [4] worked on the multiplicative degree-based TIs for tree graphs, Kwunet et al. studied the multiplicative degree-based TIs for the silicon carbides [5], Hayat et al. [6] worked on many degree-based molecular descriptors for silicates, oxides, hexagonal, and honeycombs, Darafsheh [7] introduced various suitable ways and techniques to estimate the Wiener index, Padmaker-Ivan index, 
and Szeged index, Kulli [8] wrote on F-indices on chemical networks, M. Saddiqui defined Zagreb indices for symmetrical nanotubes [9], Geo et al. worked for the Zagreb indices for the nanotubes [10], and Idrees et al. apply molecular descriptors to the benzenoid system [11]. Ayachye and Alameri [12] defined the topological indices such as Wiener index, hyper-Wiener index, Zagreb index, Schultz index, and modified Schultz index for mk graphs. Geo et al. [13] defined the eccentricity-based TIs for the class of cycloalkanes. For more studies about the TIs for chemical and other graphs, see [14-17].

\section{Preliminaries}

Let $G=(V, E)$ be a graph with $V(G)$ as vertex set and $E(G)$ as edges' set. The degree of vertex $V$ is denoted by $d(v)$ as the number of edges incident to a vertex $\mathrm{V}$. In this paper, we will discuss simple (with no loops or multiple edges), undirected (graph has no distinction between two vertices associated with each edge), and connected graph is said to be connected if there is a path between every pair vertex. In [18], Kulli et al. defined the first and second generalized multiplicative Zagreb indices:

$$
\begin{aligned}
& M_{1}(G)=\prod_{u v \varepsilon E(G)}(d(u)+d(v))^{\alpha}, \\
& M_{2}(G)=\prod_{u v \varepsilon E(G)}(d(u) \times d(v))^{\alpha} .
\end{aligned}
$$

For the properties of multiplicative Zagreb indices, see [19-22].

Multiplicative sum connectivity and multiplicative product connectivity indices are defined as

$$
\begin{aligned}
& \operatorname{SCII}(G)=\prod_{u v \varepsilon E(G)} \frac{1}{\sqrt{d(u)+d(v)}}, \\
& \operatorname{PCII}(G)=\prod_{u v \varepsilon E(G)} \frac{1}{\sqrt{d(u) \times d(v)}} .
\end{aligned}
$$

For more information, see [23].

In [24], multiplicative atomic bond connectivity index is defined as

$$
\operatorname{ABCII}(G)=\prod_{u v \varepsilon E(G)} \sqrt{\frac{d(u)+d(v)-2}{d(u) \times d(v)}} .
$$

Multiplicative geometric arithmetic index [25] and generalized multiplicative geometric arithmetic index [26] are defined as

$$
\begin{aligned}
\operatorname{GAII}(G) & =\prod_{u v \varepsilon E(G)} \frac{2 \sqrt{d(u) \times d(v)}}{d(u)+d(v)}, \\
\operatorname{GA}^{\alpha} \mathrm{II}(G) & =\prod_{u v \varepsilon E(G)}\left(\frac{2 \sqrt{d(u) \times d(v)}}{d(u)+d(v)}\right)^{\alpha} .
\end{aligned}
$$

Note: if we put (i) For $\alpha=1$, first and second generalized multiplicative Zagreb indices become first and second multiplicative Zagreb indices

(ii) For $\alpha=2$, first and second generalized multiplicative Zagreb indices become first and second hypermultiplicative Zagreb indices

(iii) For $\alpha=(-1 / 2)$, first and second generalized multiplicative Zagreb indices become multiplicative sum connectivity and multiplicative product connectivity indices.

(iv) For $\alpha=(-1 / 2)$, first and second generalized multiplicative Zagreb indices become multiplicative sum connectivity and multiplicative product connectivity indices

\section{2D Structure of Silicon Carbide for $\mathrm{SiC}_{4}-I[m, n]$}

The construction of $2 \mathrm{D}$ structure of silicon carbide for $\mathrm{SiC}_{4}-$ $I[m, n]$ is shown in Figure 1, where one unit of $\mathrm{SiC}_{4}-I[m, n]$ is displayed in (a). In this molecular graph, $m$ denotes the number of cells attached in a single row and $n$ denotes the number of total rows in which each row contains $\mathrm{m}$ cells. Figures 1(b)-1(d) indicate how unit cells are connected in one row and then one row to another row and so on. Furthermore, it is discussed how unit cell connect each other to get more columns and rows which enhance physical development of the structure $\mathrm{SiC}_{4}-I[m, n]$ with different orders.

The simple methodology of constructing chemical structure above by considering increment in number to connect the unit cells in $m$ direction increases the length of row, while increase in unit cell in $n$ style means the number of row is increasing. Consequently, the total numbers of vertices, edges, and faces in $\mathrm{SiC}_{4}-I[m, n]$ are

$$
\begin{aligned}
& \left|V\left(\mathrm{SiC}_{4}-I[m, n]\right)\right|=10 m n, \\
& \left|V\left(\mathrm{SiC}_{4}-I[m, n]\right)\right|=12 m n-m-n, \\
& \left|V\left(\mathrm{SiC}_{4}-I[m, n]\right)\right|=2 m n-m-n+2 .
\end{aligned}
$$

Later on, by changing rows and columns, we discuss the different properties of carbon and silicon structure.

3.1. Methodology of Silicon Carbide $\mathrm{SiC}_{4}-I[m, n]$ Formulas. We will make different order structures of $\mathrm{SiC}_{4}-I[m, n]$ by connecting the unit cells in different sequences, in horizontal way, and then in vertical way to form new structures. It is a very easy method to calculate the melting and boiling points and other properties of chemical structures without costly experiments.

3.2. Edge Partition for $\mathrm{SiC}_{4}-I[m, n]$. According to the end point, degrees of edges $\mathrm{SiC}_{4}-I[m, n]$ are divided into five categories.

By Table 1, the general form of edges partition with the frequency is given in Table 2 , where $m, n \geq 1$ and edge parcel $u v$ contains 2 edges when $d(u)=2$ and $d(v)=1$; other four parcels are also shown. In graph $G$ of $\mathrm{SiC}_{4}-I[m, n]$, it is 


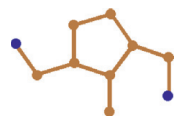

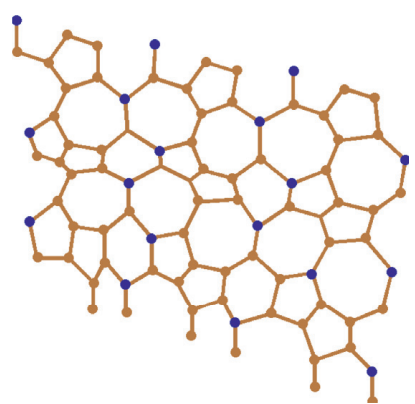

(b)
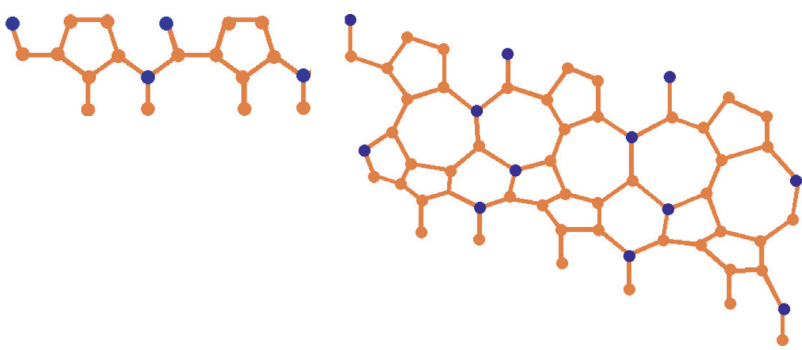

(d)

Figure 1: Two-dimensional structure of $\mathrm{SiC}_{4} I[m, n]$ : chemical unit cell of (a) $\mathrm{SiC}_{4}-I[m, n]$, (b) $\mathrm{SiC}_{4}-I[3,3],(\mathrm{c}) \mathrm{SiC}_{4}-I[3,1]$, and (d) $\mathrm{SiC}_{4}-I[3,2]$, where carbon atoms $\mathrm{C}$ are brown and silicon atoms $\mathrm{Si}$ are blue.

TABle 1: Edge partition of $\mathrm{SiC}_{4}-I[m, n]$.

\begin{tabular}{|c|c|c|c|c|c|c|c|c|c|}
\hline$[\mathrm{m}, \mathrm{n}]$ & {$[1,1]$} & {$[2,1]$} & {$[3,1]$} & {$[1,2]$} & {$[2,2]$} & {$[3,2]$} & {$[1,3]$} & {$[2,3]$} & {$[3,3]$} \\
\hline$E_{12}$ & 2 & 2 & 2 & 2 & 2 & 2 & 2 & 2 & 2 \\
\hline$E_{13}$ & 1 & 4 & 7 & 1 & 4 & 7 & 1 & 4 & 7 \\
\hline$E_{22}$ & 1 & 2 & 3 & 3 & 4 & 5 & 5 & 6 & 7 \\
\hline$E_{23}$ & 4 & 6 & 8 & 8 & 10 & 12 & 12 & 14 & 16 \\
\hline$E_{33}$ & 2 & 7 & 12 & 9 & 29 & 49 & 16 & 51 & 86 \\
\hline
\end{tabular}

TABLE 2: Edges' partition of $\mathrm{SiC}_{4}-I[m, n]$, for $m, n \geq 2$.

\begin{tabular}{lcc}
\hline Edges & $(\mathrm{d}(\mathrm{u}), \mathrm{d}(\mathrm{v}))$ & Frequency \\
\hline$E_{1}$ & $(2,1)$ & 2 \\
$E_{2}$ & $(3,1)$ & $3 \mathrm{~m}-2$ \\
$E_{3}$ & $(2,2)$ & $m+2 \mathrm{n}-2$ \\
$E_{4}$ & $(2,3)$ & $2 \mathrm{~m}+4 \mathrm{n}-2$ \\
$E_{5}$ & $(3,3)$ & $15 \mathrm{mn}-10 \mathrm{~m}-8 \mathrm{n}+5$ \\
\hline
\end{tabular}

calculated that the total number of vertices and edges are $10 m n$ and $12 m n-m-n$, respectively. Thus, the edge set of $\mathrm{SiC}_{4}-I[m, n]$ with $m, n \geq 1$ has 5 partitions.

\section{Computational Results for Silicon$$
\text { Carbide } \mathrm{SiC}_{4}-I[m, n]
$$

degree Zagreb beta index, the second ve-degree Zagreb index, ev-degree Randic index, ve-degree atom bond connectivity index, ve-degree geometric index, and ve-degree sun connectivity index of silicon carbide $\mathrm{SiC}_{4}-I[m, n]$.

Theorem 1. Let $\mathrm{SiC}_{4}-I[m, n]$ be the silicon carbide. Then,

In this partition, we compute ev-degree- and ve-degree-based topological indices such as the ev-degree Zagreb index, first ve-

$$
\begin{aligned}
M Z_{1}^{\alpha}\left(\mathrm{SiC}_{4}-I[m, n]\right) & =(2)^{\alpha(15 m n-2 m-4 n-3)} \times(3)^{\alpha(15 m n-10 m-8 n+7)} \times(5)^{\alpha(2 m+4 n-2)}, \\
M Z_{2}^{\alpha}\left(\mathrm{SiC}_{4}-I[m, n]\right) & =(2)^{4 \alpha(m+2 n-1)} \times(3)^{3 \alpha(10 m n-5 m-4 n+2)}, \\
\mathrm{GA}^{\alpha} \mathrm{II}\left(\mathrm{SiC}_{4}-I[m, n]\right) & =(\sqrt{2})^{\alpha(12 n-4)} \times(\sqrt{3})^{\alpha(5 m+4 n-8)} \times(5)^{\alpha(-2 m-4 n+2)} .
\end{aligned}
$$

Proof

$$
\begin{aligned}
M Z_{1}^{\alpha}\left(\mathrm{SiC}_{4}-I[m, n]\right) & =\prod_{u v \varepsilon E\left(\mathrm{SiC}_{4}-I[m, n]\right)}(d(u)+d(v))^{\alpha} \\
& =(2+1)^{2 \alpha} \times(2)^{\alpha(6 m-4)} \times(2)^{\alpha(2 m+4 n-4)} \times(5)^{\alpha(2 m+4 n-2)} \times(2)^{\alpha(15 m n-10 m-8 n+5)} \times(3)^{\alpha(15 m n-10 m-8 n+5)} \\
& =(2)^{\alpha(15 m n-2 m-4 n-3)} \times(3)^{\alpha(15 m n-10 m-8 n+7)} \times(5)^{\alpha(2 m+4 n-2)}
\end{aligned}
$$




$$
\begin{aligned}
M Z_{2}^{\alpha}\left(\mathrm{SiC}_{4}-I[m, n]\right) & =\prod_{u v \varepsilon E\left(\mathrm{SiC}_{4}-I[m, n]\right.}(d(u) \times d(v))^{\alpha} \\
& =(2)^{2 \alpha} \times(3)^{\alpha(3 m-2)} \times(2)^{\alpha(2 m+4 n-4)} \times(2)^{\alpha(2 m+4 n-2)} \times(3)^{\alpha(2 m+4 n-2)} \times(3)^{\alpha(30 m n-20 m-16 n+10)} \\
& =(2)^{4 \alpha(m+2 n-1)} \times(3)^{3 \alpha(10 m n-5 m-4 n+2)} \\
\mathrm{GA}^{\alpha} \mathrm{II}\left(\mathrm{SiC}_{4}-I[m, n]\right) & =\prod_{u v \varepsilon E\left(\mathrm{SiC}_{4}-I[m, n]\right)}\left(2 \frac{\sqrt{d(u) \times d(v)}}{d(u)+d(v)}\right)^{\alpha} \\
& =\left(\frac{2 \sqrt{2}}{3}\right)^{2 \alpha} \times\left(\frac{2 \sqrt{3}}{4}\right)^{\alpha(3 m-2)} \times\left(\frac{2(2)}{4}\right)^{\alpha(m+2 n-2)} \times\left(\frac{2 \sqrt{6}}{5}\right)^{\alpha(2 m+4 n-2)} \times\left(\frac{2(3)}{3+3}\right)^{\alpha(15 m n-10 m-8 n+5)} \\
& =(\sqrt{2})^{\alpha(12 n+4)} \times(\sqrt{3})^{\alpha(5 m+4 n-8)} \times(5)^{\alpha(-2 m-4 n+2)} .
\end{aligned}
$$

Theorem 2. Let $\left(\mathrm{SiC}_{4}-I[m, n]\right)$ be the silicon carbide. Then,

$$
\begin{aligned}
& M Z_{1}\left(\mathrm{SiC}_{4}-I[m, n]\right)=(2)^{(15 m n-2 m-4 n-3)} \times(3)^{(15 m n-10 m-8 n+7)} \times(5)^{(2 m+4 n-2)} \\
& M Z_{2}\left(\mathrm{SiC}_{4}-I[m, n]\right)=(2)^{4(m+2 n-1)} \times(3)^{3(10 m n-5 m-4 n+2)} \\
& \operatorname{GAII}\left(\mathrm{SiC}_{4}-I[m, n]\right)=(\sqrt{2})^{(12 n-4)} \times(\sqrt{3})^{(5 m+4 n-8)} \times(5)^{(-2 m-4 n+2)}
\end{aligned}
$$

Proof. Taking $\alpha=1$ in Theorem 1, we get results.

Theorem 3. Let $\mathrm{SiC}_{4}-I[m, n]$ be the silicon carbide. Then,

$$
\begin{aligned}
& \mathrm{HII}_{1}\left(\mathrm{SiC}_{4}-I[m, n]\right)=(2)^{2(15 m n-2 m-4 n-3)} \times(3)^{2(15 m n-10 m-8 n+7)} \times(5)^{2(2 m+4 n-2)}, \\
& \mathrm{HII}_{2}\left(\mathrm{SiC}_{4}-I[m, n]\right)=(2)^{8(m+2 n-1)} \times(3)^{6(10 m n-5 m-4 n+2)} .
\end{aligned}
$$

Proof. Taking $\alpha=2$ in Theorem 1, we get results.

Theorem 4. Let $\left(\mathrm{SiC}_{4}-I[m, n]\right)$ be the silicon carbide. Then,

$$
\begin{aligned}
& \operatorname{SCII}\left(\mathrm{SiC}_{4}-I[m, n]\right)=\left(\frac{1}{\sqrt{2}}\right)^{(15 m n-2 m-4 n-3)} \times\left(\frac{1}{\sqrt{3}}\right)^{(15 m n-10 m-8 n+7)} \times\left(\frac{1}{\sqrt{5}}\right)^{(2 m+4 n-2)}, \\
& \operatorname{PCII}\left(\mathrm{SiC}_{4}-I[m, n]\right)=\left(\frac{1}{\sqrt{2}}\right)^{4(m+2 n-1)} \times\left(\frac{1}{\sqrt{3}}\right)^{3(10 m n-5 m-4 n+2)} .
\end{aligned}
$$


Proof. Taking $\alpha=(-1 / 2)$ in Theorem 1,

$$
\begin{aligned}
\operatorname{SCII}\left(\mathrm{SiC}_{4}-I[m, n]\right) & =(2)^{(-1 / 2)(15 m n-2 m-4 n-3)} \times(3)^{(-1 / 2)(15 m n-10 m-8 n+7)} \times(5)^{(-1 / 2)(2 m+4 n-2)} \times\left(\frac{1}{\sqrt{3}}\right)^{(15 m n-10 m-8 n+7)} \times\left(\frac{1}{\sqrt{5}}\right)^{(2 m+4 n-2)}, \\
& =\left(\frac{1}{\sqrt{2}}\right)^{(15 m n-2 m-4 n-3)}, \\
\operatorname{PCII}\left(\mathrm{SiC}_{4}-I[m, n]\right) & =(2)^{4(-1 / 2)(m+2 n-1)} \times(3)^{3(-1 / 2)(10 m n-5 m-4 n+2)} \\
& =\left(\frac{1}{\sqrt{2}}\right)^{4(m+2 n-1)} \times\left(\frac{1}{\sqrt{3}}\right)^{3(10 m n-5 m-4 n+2)}
\end{aligned}
$$

Theorem 5. Let $\mathrm{SiC}_{4}-I[m, n]$ be a graph of silicon carbide.

Then,

$$
\operatorname{ABCII}\left(\mathrm{SiC}_{4}-I[m, n]\right)=\left(\frac{1}{\sqrt{2}}\right)^{(3 m+6 n-2)} \times\left(\frac{2}{3}\right)^{(3 / 2)(15 m n-7 m-8 n+3)}
$$

Proof.

$$
\begin{aligned}
\operatorname{ABCII}\left(\mathrm{SiC}_{4}-I[m, n]\right) & =\prod_{u v \varepsilon E S_{1} C_{4}-I[m, n]} \sqrt{\frac{d(u)+d(v)-2}{d(u) \times d(v)}} \\
& =\left(\sqrt{\frac{1}{2}}\right)^{2} \times\left(\sqrt{\frac{2}{3}}\right)^{(3 m-2)} \times\left(\sqrt{\frac{2}{4}}\right)^{(m+2 n-2)} \times\left(\sqrt{\frac{3}{6}}\right)^{(2 m+4 n-2)} \times\left(\sqrt{\frac{4}{9}}\right)^{(15 m n-10 m-8 n+5)} \\
& =\left(\frac{1}{\sqrt{2}}\right)^{(3 m+6 n-2)} \times\left(\frac{2}{3}\right)^{(3 / 2)(15 m n-7 m-8 n+3)}
\end{aligned}
$$

4.1. Discussion and Graphical Representations. In this section, we discuss graphs related to multiplicative degreebased topological indices which notify the variation in the characteristics of $\mathrm{SiC}_{4}-I[m, n]$.

Figure 2 graphs are panned drawing formed by lines and points used to express the specific sequence in data and information. As graphs have different dimensions, accordingly, the used parameter such as in Figure 2 all graphs of silicon carbide are three dimensional. We have seven graphs in Figure 2 (say 2(a), 2(b), 2(c), 2(d), 2(e), 2(f), and 2(g)) representing first multiplicative Zagreb index $\left(M Z_{1}\right)$, second multiplicative Zagreb index $\left(M Z_{2}\right)$, multiplicative geometric arithmetic index $\left(\mathrm{GA}^{\alpha} \mathrm{II}(G)\right)$, first and second hyper-Zagreb index, sum connectivity, and product connectivity index $(\operatorname{SCII}(G)$ and $\operatorname{PCII}(G)$ ), respectively. Our parameters have ranged from zero to one in which most of the changes in our graphs (including in Figure 2) occur in constant behavior. For instant, in Figure 2(a), multiplicative first Zagreb index $\left(M Z_{1}\right)$ shows mode straight from 0 to 1 and then increasing uniformly. All the graphs except Figure 2(c) are derived from generalized Zagreb index.
Zagreb index (ZI) is very useful, old, and effective graph parameter. It is used in network theory, molecular chemistry, and many branches of mathematics, drugs and organic chemistry. It is also used for the measurement of Skelton of branching of carbon atoms and $\pi$-electron energy in the organic compounds in chemistry. These graphs first decrease and then increase quickly which means the values of ZI are changes with respect to our parameters $m$ and $n$. In graph in Figure 2(c), by increasing the values of $m$ and $n$, multiplicative geometric arithmetic (GAII $\left.\left(\mathrm{SiC}_{4}-I[m, n]\right)\right)$ index also increases. The GA index is beneficial to find Kovats constants and boiling points of molecules.

\section{2D Structure of Silicon Carbide $\mathrm{SiC}_{4}-\mathbf{I I}[m, n]$}

The 2D molecular structure of $\mathrm{SiC}_{4}-\mathrm{II}[m, n]$ is given in Figures 3 and 4, respectively. As the unit cell is the basic of any structure which provides building blocks of the chemical structures, if we connect the unit cells in $m$ direction, then it increases the length of row, while if it increases unit cell in $n$ style, then it enhances the number of rows. 


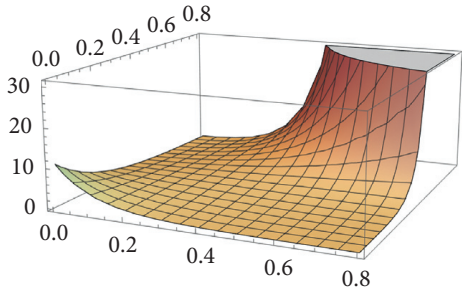

(a)

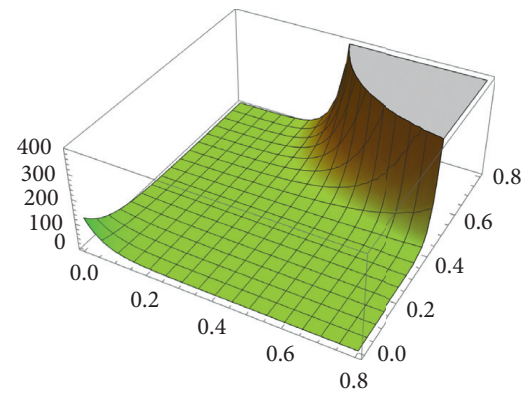

(d)

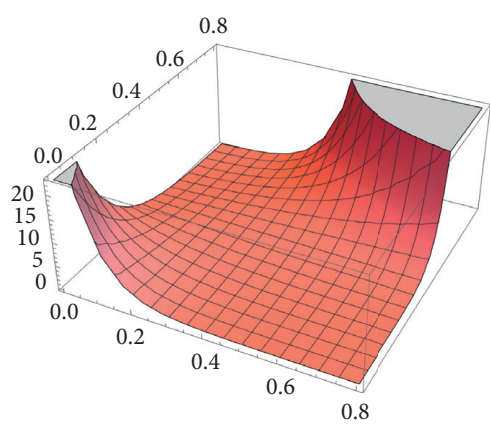

(b)

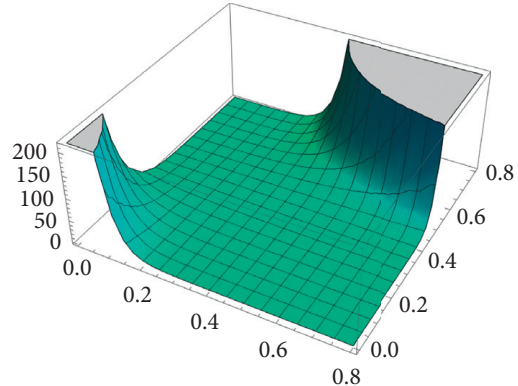

(e)

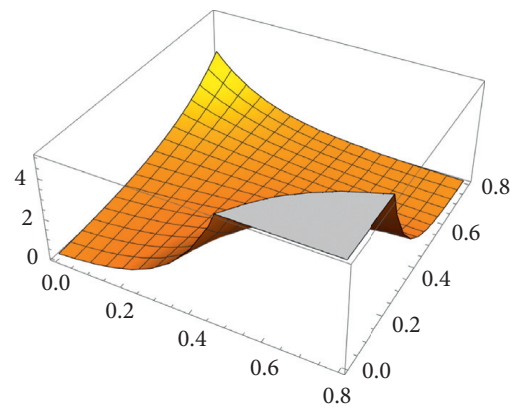

(g)

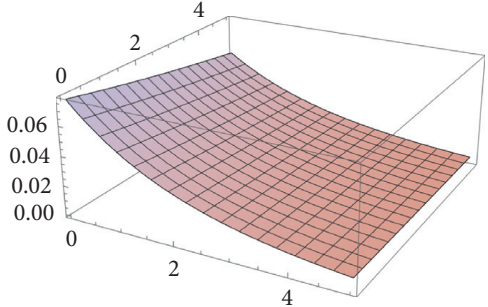

(c)

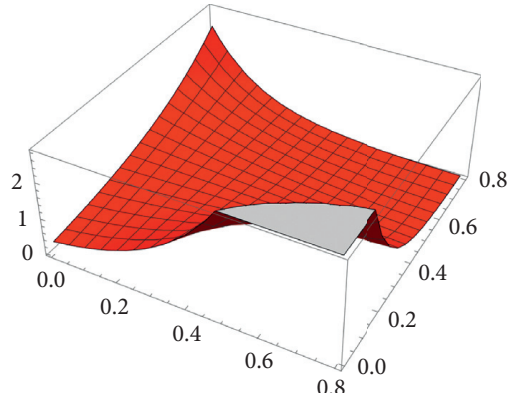

(f)

FiguRE 2: The graph of seven multiplicative degree-based topological indices for the silicon carbide $\operatorname{SiC}_{4}-I[m, n]$ described for $0 \leq m$ and $n \leq 0.8$. (a) $M Z_{1}$ for $\mathrm{SiC}_{4}-I[m, n]$. (b) $M Z_{2}$ for $\mathrm{SiC}_{4}-I[m, n]$. (c)GAII for $\mathrm{SiC}_{4}-I[m, n]$. (d)HII for $\mathrm{SiC}_{4}-I[m, n]$. (e)HII for $\mathrm{SiC}_{4}-I[m, n]$. (f)SCII for $\mathrm{SiC}_{4}-I[m, n]$. (g)PCII for $\mathrm{SiC}_{4}-I[m, n]$.

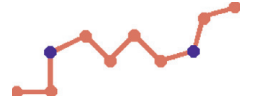

(a)

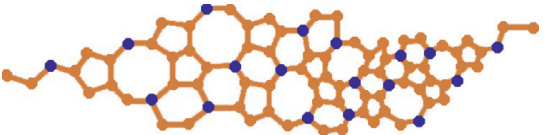

(b)

Figure 3: Two-dimensional structure of $\mathrm{SiC}_{4}-\mathrm{II}[m, n]$. (a) A unit cell of $\mathrm{SiC}_{4}-\mathrm{II}[m, n]$. (b)SiC $4-\mathrm{II}[m, n]$ for $m=3$ and $n=3$.

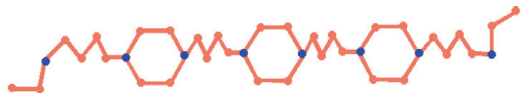

(a)

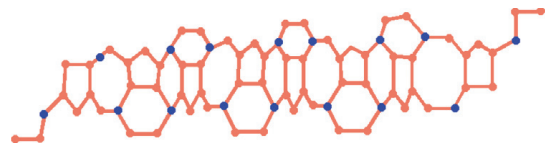

(b)

FIgURE 4: $\mathrm{SiC}_{4}-\mathrm{II}[m, n]$, two rows connected each other by edges, where $m=4$ and $n=1$. (a) $\mathrm{SiC}_{4}-\operatorname{II}[m, n]$, one row with $m=4$ and $n=1$. (b) $\mathrm{SiC}_{4}-\mathrm{II}[m, n]$ for $m=3$ and $n=3$. 
The quantity of vertices and edges in $\mathrm{SiC}_{4}-\mathrm{II}[m, n]$ are represented as

$$
\begin{aligned}
\left|V\left(\mathrm{SiC}_{4}-\mathrm{II}[m, n]\right)\right| & =10 m n, \\
\left|E\left(\mathrm{SiC}_{4}-\mathrm{II}[m, n]\right)\right| & =15 m n-4 m-2 n .
\end{aligned}
$$

5.1. Methodology of Silicon Carbide $\mathrm{SiC}_{4}-\mathrm{II}[m, n]$ and Formula. For the derivation of the formulae, firstly, use unit cell and then combine it to make different order structures of $\mathrm{SiC}_{4}-\mathrm{II}[m, n]$. If we connect the unit cells in the horizontal way up to $m$ unit cells, then we connect these unit cells in a vertical way up to $n$, and we obtained various form of chemical graph of $\mathrm{SiC}_{4}-\mathrm{II}[m, n]$, as shown previously in Figures 3 and 4. For this, MATLAB is basically used for the generalizing of formulas, where the generalized formula can be found by the calculations.

5.2. Edge Partition of $\mathrm{SiC}_{4}-I I[m, n]$. In order to find the other topological indices, we make partition of the edges of $\mathrm{SiC}_{4}-\mathrm{II}[m, n]$. By using combinatorial counting and standard edge partition, one can find the generalizing formulae of the edge partition for $\mathrm{SiC}_{4}-\mathrm{II}[m, n]$. There are total four different edge parcels in the case of $\mathrm{SiC}_{4}-\mathrm{II}[m, n]$.
The first parcel contains only 2 edges uv, where $d(u)=1$ and $d(v)=2$, while in second parcel, there are $2 \mathrm{~m}+2$ edges uv, where $d(u)=2$ and $d(v)=2$. Furthermore, third parcel contains $12 \mathrm{~m}+8 \mathrm{n}-14$ edges $u v$, where $d(u)=2$ and $d(v)=3$, and in the final parcel, the number of edges $u v$ are $15 \mathrm{mn}$ $10 \mathrm{n}-18 \mathrm{~m}+10$ with both degrees of 3 as given in Table 3 . Consider $G$ as the graph of $\mathrm{SiC}_{4}-\mathrm{II}[m, n]$ (see Figures 3 and 4 ) and note that the total number of vertices, edges, and faces are $10 m n, 15 m n-4 m-2 n$, and $5 m n-4 m-2 n+2$, respectively. Thus, the edge set of $\mathrm{SiC}_{4}-\mathrm{II}[m, n]$ with $m, n \geq 1$ has 4 partitions.

\section{Computational Results for Silicon Carbide $\mathrm{SiC}_{4}-\mathbf{I I}[m, n]$}

In this partition, we compute ev-degree- and ve-degree-based topological indices such as the ev-degree Zagreb index, first ve-degree Zagreb beta index, the second ve-degree Zagreb index, ev-degree Randic index, ve-degree atom bond connectivity index, ve-degree geometric index, and ve-degree sum connectivity index for silicon carbide $\mathrm{SiC}_{4}-\mathrm{II}[m, n]$.

Theorem 6. Let $\mathrm{SiC}_{4}-I I[m, n]$ be the silicon carbide. Then,

$$
\begin{aligned}
M Z_{1}^{\alpha}\left(\mathrm{SiC}_{4}-\mathrm{II}[m, n]\right) & =(2)^{\alpha(15 m n-14 m-10 n+14)} \times(3)^{\alpha(15 m n-18 m-10 n+12)} \times(5)^{2 \alpha(6 m+4 n-7)}, \\
M Z_{2}^{\alpha}\left(\mathrm{SiC}_{4}-\mathrm{II}[m, n]\right) & =(2)^{8 \alpha(2 m+n-1)} \times(3)^{6 \alpha(5 m n-4 m-2 n+4)} \\
\mathrm{GA}^{\alpha} \mathrm{II}\left(\mathrm{SiC}_{4}-\mathrm{II}[m, n]\right) & =(2)^{\alpha(18 n+12 n-18)} \times(3)^{\alpha(6 m+4 n-9)} \times(5)^{\alpha(-12 m-8 n+14)}
\end{aligned}
$$

Proof.

$$
\begin{aligned}
M Z_{1}^{\alpha}\left(\mathrm{SiC}_{4}-\mathrm{II}[m, n]\right) & =\prod_{u v \varepsilon E\left(\mathrm{SiC}_{4}-\mathrm{II}[m, n]\right)}(d(u)+d(v))^{\alpha} \\
& =(3)^{2 \alpha} \times(2)^{2 \alpha(2 m+2)} \times(5)^{\alpha(12 m+8 n-14)} \times(2)^{\alpha(15 m n-10 n-18 m+10)} \times(3)^{\alpha(15 m n-10 n-18 m+10)} \\
& =(2)^{\alpha(15 m n-14 m-10 n+14)} \times(3)^{\alpha(15 m n-18 m-10 n+12)} \times(5)^{2 \alpha(6 m+4 n-7)} \\
\mathrm{MZ}_{2}^{\alpha}\left(\mathrm{SiC}_{4}-\mathrm{II}[m, n]\right) & =\prod_{u v \varepsilon E\left(\mathrm{SiC}_{4}-\mathrm{II}[m, n]\right)}(d(u) \times d(v))^{\alpha} \\
& =(2)^{2 \alpha} \times(2)^{2 \alpha(2 m+2)} \times(2)^{\alpha(12 m+8 n-14)} \times(3)^{\alpha(12 m+8 n-14)} \times(3)^{2 \alpha(15 m n-10 n-18 m+10)} \\
& =(2)^{8 \alpha(2 m+n-1)} \times(3)^{6 \alpha(5 m n-4 m-2 n+4)}, \\
\mathrm{GA}^{\alpha} \mathrm{II}\left(\mathrm{SiC}_{4}-\mathrm{II}[m, n]\right)= & u v \varepsilon E\left(\operatorname{SiC}_{4}-\mathrm{II}[m, n]\right) \\
= & \left.\left(\frac{2 \sqrt{2}}{3}\right)^{2 \alpha} \times\left(\frac{\sqrt{d(u) \times d(v)}}{d(u)+d(v)}\right)^{\alpha}\right)^{\alpha(2 m+2)} \times\left(\frac{2 \sqrt{2} \sqrt{3}}{5}\right)^{\alpha(12 m+8 n-14)} \times\left(\frac{2(3)}{6}\right)^{\alpha(15 m n-10 n-18 m+10)} \\
= & (2)^{\alpha(18 m+12 n-18)} \times(3)^{\alpha(6 m+4 n-9)} \times(5)^{\alpha(-12 m-8 n+14)}
\end{aligned}
$$


TABLe 3: Edges' partition of $\mathrm{SiC}_{4}-\mathrm{II}[m, n]$.

\begin{tabular}{lcc}
\hline Edges & $(d(u), d(v))$ & Frequency \\
\hline$E_{1}$ & $(1,2)$ & 2 \\
$E_{2}$ & $(2,2)$ & $2 m+2$ \\
$E_{3}$ & $(2,3)$ & $12 m+8 n-14$ \\
$E_{4}$ & $(3,3)$ & $15 m n-10 n-18 m+10$ \\
\hline
\end{tabular}

Theorem 7. Let $\left(\mathrm{SiC}_{4}-\mathrm{II}[m, n]\right)$ be the silicon carbide.

Then,

$$
\begin{aligned}
& M Z_{1}\left(\mathrm{SiC}_{4}-\mathrm{II}[m, n]\right)=(2)^{(15 m n-14 m-10 n+14)} \times(3)^{(15 m n-18 m-10 n+12)} \times(5)^{2(6 m+4 n-7)}, \\
& M Z_{2}\left(\mathrm{SiC}_{4}-\mathrm{II}[m, n]\right)=(2)^{8(2 m+n-1)} \times(3)^{6(5 m n-4 m-2 n+4)} \\
& \operatorname{GAII}\left(\mathrm{SiC}_{4}-\mathrm{II}[m, n]\right)=(2)^{\alpha(18 m+12 n-18)} \times(3)^{\alpha(6 m+4 n-9)} \times(5)^{\alpha(-12 m-8 n+14)} .
\end{aligned}
$$

Proof. Taking $\alpha=1$ in Theorem 6, we get results.

Theorem 8. Let $\mathrm{SiC}_{4}-I I[m, n]$ be the silicon carbide. Then,

$$
\begin{aligned}
& \mathrm{HII}_{1}\left(\mathrm{SiC}_{4}-\mathrm{II}[m, n]\right)=(2)^{2(15 m n-14 m-10 n+14)} \times(3)^{2(15 m n-18 m-10 n+12)} \times(5)^{4(6 m+4 n-7)}, \\
& \mathrm{HII}_{2}\left(\mathrm{SiC}_{4}-\mathrm{II}[m, n]\right)=(2)^{16(2 m+n-1)} \times(3)^{12(5 m n-4 m-2 n+4)}
\end{aligned}
$$

Proof. Taking $\alpha=2$ in Theorem 4.6, we get results.

Theorem 9. Let $\mathrm{SiC}_{4}-I I[m, n]$ be the silicon carbide. Then,

$$
\begin{aligned}
& \operatorname{SCII}\left(\mathrm{SiC}_{4}-\mathrm{II}[m, n]\right)=\left(\frac{1}{\sqrt{2}}\right)^{(15 m n-14 m-10 n+14)} \times\left(\frac{1}{\sqrt{3}}\right)^{(15 m n-18 m-10 n+12)} \times\left(\frac{1}{\sqrt{5}}\right)^{2(6 m+4 n-7)}, \\
& \operatorname{PCII}\left(\mathrm{SiC}_{4}-\mathrm{II}[m, n]\right)=\left(\frac{1}{\sqrt{2}}\right)^{8(2 m+n-1)} \times\left(\frac{1}{\sqrt{3}}\right)^{6(5 m n-4 m-2 n+4)} .
\end{aligned}
$$

Proof. Using $\alpha=(-1 / 2)$ in Theorem 4.6, we obtain

$$
\begin{aligned}
\operatorname{SCII}\left(\mathrm{SiC}_{4}-\mathrm{II}[m, n]\right) & =(2)^{(-1 / 2)(15 m n-14 m-10 n+14)} \times(3)^{(-1 / 2)(15 m n-18 m-10 n+12)} \times(5)^{2(-1 / 2)(6 m+4 n-7)} \times\left(\frac{1}{\sqrt{3}}\right)^{(15 m n-18 m-10 n+12)} \times\left(\frac{1}{\sqrt{5}}\right)^{2(6 m+4 n-7)} \\
& =\left(\frac{1}{\sqrt{2}}\right)^{(15 m n-14 m-10 n+14)} \\
\operatorname{PCII}\left(\mathrm{SiC}_{4}-\mathrm{II}[m, n]\right) & =(2)^{8(-1 / 2)(2 m+n-1)} \times(3)^{6(-1 / 2)(5 m n-4 m-2 n+4)} \\
& =\left(\frac{1}{\sqrt{2}}\right)^{8(2 m+n-1)} \times\left(\frac{1}{\sqrt{3}}\right)^{6(5 m n-4 m-2 n+4)}
\end{aligned}
$$

Theorem 10. Let $\mathrm{SiC}_{4}-I I[m, n]$ be the silicon carbide. Then,

$$
\operatorname{ABCII}\left(\mathrm{SiC}_{4}-\mathrm{II}[m, n]\right)=\left(\frac{1}{\sqrt{2}}\right)^{(-30 m n+50 m+28 n-30)} \times\left(\frac{1}{\sqrt{3}}\right)^{(30 m n-36 m-20 n+20)} .
$$




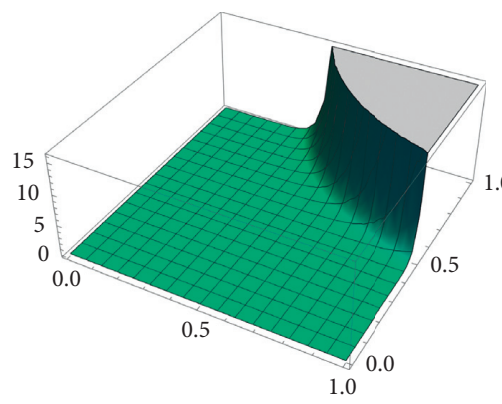

(a)

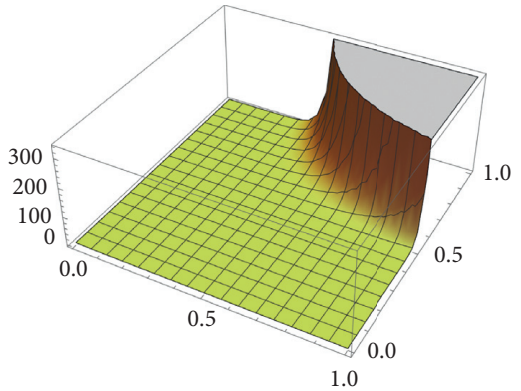

(d)

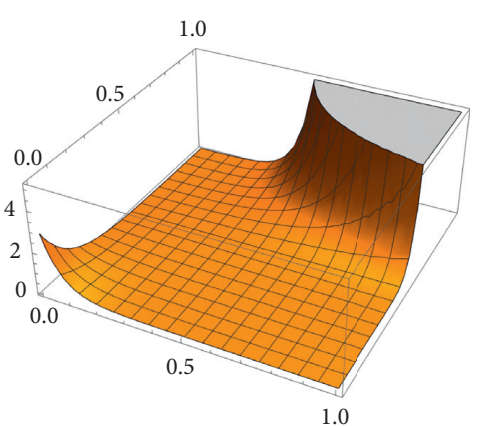

(b)

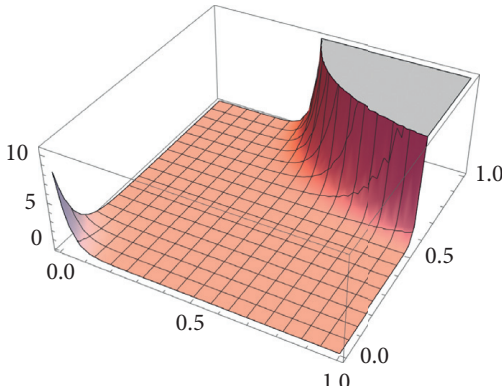

(e)

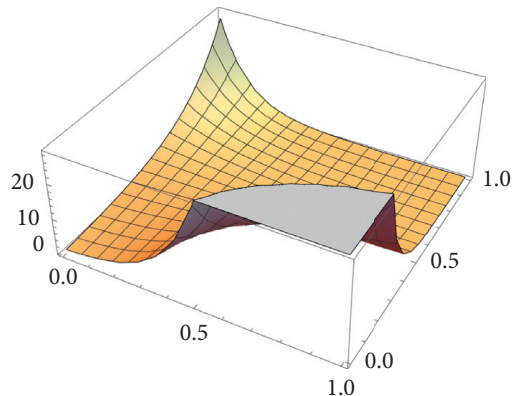

(g)

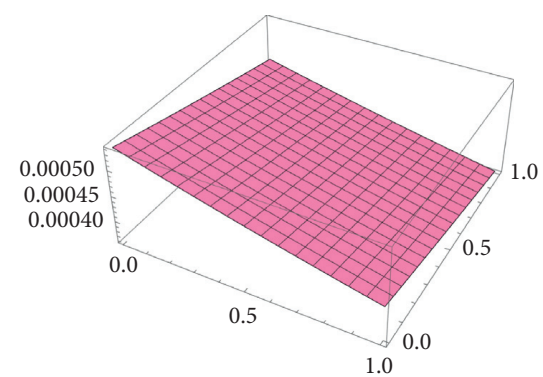

(c)

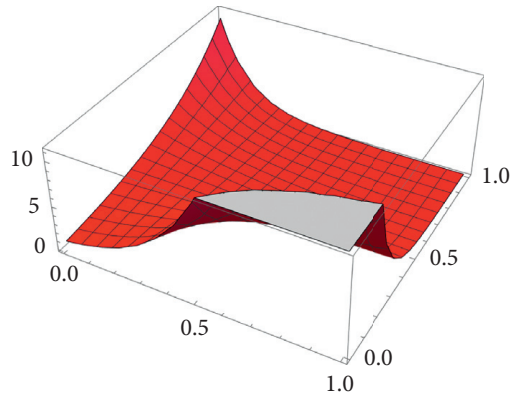

(f)

Figure 5: The graph of seven multiplicative degree-based topological indices for the silicon carbide $\mathrm{SiC}_{4}-\mathrm{II}[m, n]$ are described above for $0 \leq m, n \leq 0.8$. (a) $M Z_{1}$ for $\mathrm{SiC}_{4}-\mathrm{II}[m, n]$. (b) $M Z_{2}$ for $\mathrm{SiC}_{4}-\mathrm{II}[m, n]$. (c)GAII for $\mathrm{SiC}_{4}-\mathrm{II}[m, n]$. (d)HII for $\mathrm{SiC}_{4}-\mathrm{II}_{1}[m, n]$. (e)HII ${ }_{2}$ for $\mathrm{SiC}_{4}-\mathrm{II}[m, n]$. (f)SCII for $\mathrm{SiC}_{4}-\mathrm{II}[m, n]$. (g)PCII for $\mathrm{SiC}_{4}-\mathrm{II}[m, n]$.

Proof.

$$
\begin{aligned}
\operatorname{ABCII}\left(\mathrm{SiC}_{4}-\mathrm{II}[m, n]\right) & =\prod_{u v \varepsilon E\left(\mathrm{SiC}_{4}-\mathrm{II}[m, n]\right)} \sqrt{\frac{d(u)+d(v)-2}{d(u) \times d(v)}} \\
& =\left(\frac{1}{\sqrt{2}}\right)^{2} \times\left(\sqrt{\frac{1}{2}}\right)^{(2 m+2)} \times\left(\frac{1}{\sqrt{2}}\right)^{(12 m+8 n-14)} \times\left(\frac{2}{3}\right)^{(15 m n-18 m-10 n+10)} \\
& =\left(\frac{1}{\sqrt{2}}\right)^{(-30 m n+50 m+28 n-30)} \times\left(\frac{1}{\sqrt{3}}\right)^{(30 m n-36 m-20 n+20)} .
\end{aligned}
$$

6.1. Discussion and Graphical Representations. The graphs given in Figure 5 tell us about the behavior of different multiplicative degree-based topological indices of silicon carbide $\mathrm{SiC}_{4}-\mathrm{II}[m, n]$. Silicon carbide is a semiconductor with many isomers used in almost all electronic gadgets. The range of our parameters is from zero to one. Most of the changes that occur in this range than graphs show constant behavior. In Figure 5(a), multiplicative first Zagreb index is 
discussed, where graph from 0 to 1 is straight and constantly uniform and then it eventually increases. The GA index is the extended form of the Randic index which gives faster and better information about the physical and chemical properties of compounds. By increasing the values of $m$ and $n$, the graph also increase which means the values of boiling points of $\mathrm{SiC}_{4}-\mathrm{II}[m, n]$ also increase. Other graphs describe the variation in the values of Zagreb indices by increasing $m$ and $n$.

\section{Conclusion}

The graph is an easy way to describe chemistry of relationship in data. Graph is used to present numerous or complicated data in a picture form in less space and has lots of application in almost every field of science. We have discussed many graphical invariants (topological indices) above which considered fixed numbers related to the graphs of chemical structures. We have studied the behavior of different multiplicative versions of degree-based topological indices such as first $\left(M Z_{1}\right)$ and $\left(M Z_{2}\right)$ second Zagreb indices, first and second hyper-Zagreb indices, geometric arithmetic index (GAII), atom bond connectivity index $\left(\mathrm{HII}_{1}\right)$ and $\left(\mathrm{HII}_{2}\right)$, and sum (SCII) and product connectivity (PCII)index of silicon carbide $\mathrm{SiC}_{4}-\mathrm{II}[m, n]$.

\section{Data Availability}

No data were used to support the findings of the study.

\section{Conflicts of Interest}

The authors declare that they have no conflicts of interest.

\section{References}

[1] K. Yenoke, K. M. Kaabar, M. M. Ali Al-Shamiri, and R. C. Thivyarathi, "Radial Radio number of hexagonal and its derived networks," International Journal of Mathematics and Mathematical Sciences, vol. 2021, Article ID 5101021, 8 pages, 2021.

[2] K. Yenoke and K. M. Kaabar, "The bounds for the distance two labelling and radio labelling of nanostar tree dendrimer," Journal of the American Chemical Society, vol. 69, pp. 17-20, 2021.

[3] I. Gutman, Ruscic, B. Trinajstc, and N. Wilcox, "Graph theory and molecular orbitals. XII. Acyclic polyenes," The Journal of Chemical Physics, vol. 62, no. 9, pp. 3399-4340, 1975.

[4] I. Gutman, "Multiplicative Zagreb indices of trees," Bulletin of International Mathematical Virtual Institute, vol. 18, pp. 1723, 2011.

[5] Y. Kwun, A. Virk, W. Nazeer, M. Rehman, and S. Kang, "On the multiplicative degree-based topological indices of siliconcarbon Si2C3-I $[p, q]$ and Si2C3-II $[p, q]$," Symmetry, vol. 10, no. 8 , p. $320,2018$.

[6] S. Hayat and M. Imran, "Computation of topological indices of certain networks," Applied Mathematics and Computation, vol. 240, pp. 213-228, 2014.

[7] M. R. Darafsheh, "Computation of topological indices of some graphs," Acta Applicandae Mathematicae, vol. 110, no. 3, pp. 1225-1235, 2010.
[8] V. R. Kulli, "F-indices of chemical networks," International Journal of Mathematical Archive, vol. 10, pp. 21-30, 2019.

[9] Z. Shao, M. Siddiqui, and M. Muhammad, "Computing Zagreb indices and Zagreb polynomials for symmetrical nanotubes," Symmetry, vol. 10, no. 7, pp. 244-254, 2018.

[10] W. Gao, M. R. Farahani, M. K. Jamil, and M. K. Siddiqui, "The redefined first, second and third Zagreb indices of titania nanotubes $\mathrm{TiO} 2[m, n]$," The Open Biotechnology Journal, vol. 10, no. 1, pp. 272-277, 2016.

[11] N. Idrees, M. N. Naeem, F. Hussain, A. Sadiq, and M. K. Siddiqui, "Molecular descriptors of benzenoid system," Quimica Nova, vol. 40, pp. 143-145, 2017.

[12] A. Ayache and A. Alameri, "Topological indices of the -graph," Journal of the Association of Arab Universities for Basic and Applied Sciences, vol. 24, no. 1, pp. 283-291, 2017.

[13] W. Gao, Y. Chen, and W. Wang, "The topological variable computation for a special type of cycloalkanes," Journal of Chemistry, vol. 2017, Article ID 6534758, 8 pages, 2017.

[14] M. Perc, J. Gmez-Gardes, A. Szolnoki, L. M. Flora, and Y. Moreno, "Evolutionary dynamics of group interactions on structured populations, a review," Journal of The Royal Society Interface, vol. 10, 2013.

[15] Z. Wang, A. Szolnoki, and M. Perc, "If players are sparse social dilemmas are too: importance of percolation forevolution of cooperation," Scientific Reports, vol. 2, 2012.

[16] M. Bacca, J. Horvthov, M. Mokriov, and A. Suhnyiov, "On topological indices of fullerenes," Applied Mathematics and Computation, vol. 251, pp. 154-161, 2015.

[17] S. M. Kamran, S. Manzoor, S. Ahmad, and K. M. Kaabar, "On computation and analysis of entropy measures for crystal structures," Mathematical Problems in Engineering, vol. 2021, Article ID 9936949, 16 pages, 2021.

[18] V. R. Kulli, B. Stone, S. Wang, and B. Wei, "Generalised multiplicative indices of polycyclic aromatic hydrocarbons and benzenoid systems," Zeitschrift für Naturforschung A, vol. 72, no. 6, pp. 573-576, 2017.

[19] C. D. Kinker, Y. Aysun, and N. C. Ismail, "The multiplicative Zagreb indices of graph operations," Journal of Inequalities and Applications, vol. 90, pp. 1-8, 2013.

[20] I. Gutman, "Multiplicative Zagreb indices of trees," Bulletin of the International Mathematical Virtual Institute, vol. 18, pp. 17-23, 2011.

[21] M. Eliasi, A. Iranmanes, and S. Gutmans, "Multiplicative version of first Zagreb index, MATCH common," MATCH Communications in Mathematical and in Computer Chemistry, vol. 68, pp. 217-230, 2012.

[22] S. Wang and B. Wei, "Multiplicative Zagreb indices of k-trees," Discrete Applied Mathematics, vol. 180, pp. 168-175, 2015.

[23] V. R. Kulli, "Multiplicative connectivity indices of TUC4C8 $[m, n]$ and TUC4 $[m, n]$ nanotubes," Journal of Mathematical and Computational Science, vol. 7, pp. 599-605, 2016.

[24] V. R. Kulli, "New connectivity topological indices," Annals of pure and applied mathematics, vol. 20, no. 1, pp. 1-2, 2019.

[25] I. Gutman, A. Merve, and I. N. Cangul, "Multiplicative geometric arithmetic index," International Journal of Applied graph theory, vol. 2, no. 2, pp. 16-28, 2018.

[26] V. R. Kulli, "Some new multiplicative geometric-arithmetic indices," Journal of Ultra Scientist of Physical Sciences Section A, vol. 29, no. 2, pp. 52-57, 2017. 